AperTO - Archivio Istituzionale Open Access dell'Università di Torino

\title{
Borrelia lusitaniae OspA gene heterogeneity in Mediterranean basin area
}

\section{This is the author's manuscript}

Original Citation:

Availability:

This version is available http://hdl.handle.net/2318/36548

since 2016-11-29T17:28:11Z

Terms of use:

Open Access

Anyone can freely access the full text of works made available as "Open Access". Works made available under a Creative Commons license can be used according to the terms and conditions of said license. Use of all other works requires consent of the right holder (author or publisher) if not exempted from copyright protection by the applicable law. 


\title{
Borrelia lusitaniae OspA Gene Heterogeneity in Mediterranean Basin Area
}

\author{
Elena Grego $\cdot$ Luigi Bertolotti · Simone Peletto · Giuseppina Amore · \\ Laura Tomassone $\cdot$ Alessandro Mannelli
}

Received: 28 February 2007 / Accepted: 31 July 2007/Published online: 26 September 2007

(C) Springer Science+Business Media, LLC 2007

\begin{abstract}
In this study, Borrelia lusitaniae DNA extracted from ticks and lizards was used to amplify the outer surface protein A (OspA) gene in order to increase knowledge about sequence variability in the Mediterranean basin area, to better understand how Borrelia lusitaniae has evolved and how its distribution has expanded. Phylogenetic trees including Italian and reference sequences showed a clear separation of B. lusitaniae OspA strains in two different major clades. North African isolates form a clade with Portuguese POTIB strains, whereas Italian samples are grouped with German strains and a human Portuguese strain. This subdivision was supported by very high posterior probability values in the trees, by both analysis of molecular variance and selective pressure. These results, based on phylogenetic information contained in the OspA gene sequences, show the presence of two different $B$. lusitaniae strains circulating in the Mediterranean basin area, suggesting two different evolution paths.
\end{abstract}

Keywords Borrelia lusitaniae - OspA · Phylogenetics . Analysis of molecular variance

E. Grego $\cdot$ L. Bertolotti $(\bowtie) \cdot$ G. Amore $\cdot$ L. Tomassone

A. Mannelli

Dipartimento di Produzioni Animali, Epidemiologia, Ecologia,

Facoltà di Medicina Veterinaria, Università degli Studi di

Torino, Via Leonardo da Vinci 44, 10095 Grugliasco, TO, Italy

e-mail: luigi.bertolotti@unito.it

\section{S. Peletto}

CEA (National Reference Centre for TSEs),

Istituto Zooprofilattico Sperimentale del Piemonte,

Liguria e Valle d'Aosta, via Bologna 148, 10154 Turin, Italy

\section{Introduction}

Lyme borreliosis (LB) is the most commonly reported tickborne zoonosis in Europe and North America and it is caused by spirochetes included in B. burgdorferi sensu lato (s.l.) complex. Eleven different genospecies belong to this group, of which B. afzelii, B. burgdorferi sensu stricto, B. garinii, and probably also $B$. valaisiana have been demonstrated to be pathogenic (Wang et al. 1999). Furthermore, recent studies have identified Borrelia lusitaniae as a potential agent of Lyme disease. The first human isolate of $B$. lusitaniae was identified in a 46-year-old woman from the Lisbon area in Portugal (Collares-Pereira et al. 2004). Such genospecies are the most prevalent in the Mediterranean area (Collares-Pereira et al. 2004; Sarih et al. 2003; Younsi et al. 2005) and recent studies indicate lizards as the reservoir hosts (Amore et al. 2007; Majlathova et al. 2006; Richter and Matuschka 2006; Tomassone et al. 2005; Younsi et al. 2005).

In Italy, B. lusitaniae is the dominant genospecies in hostseeking Ixodes ricinus ticks (Bertolotti et al. 2006) and in ticks from lizards (Amore et al. 2007) on Le Cerbaie Hills, in the province of Pisa, Tuscany. At the same location, a case of Lyme borreliosis was reported in a forestry worker in 2001. First, B. lusitaniae isolates collected from ticks in Europe showed no significant diversity (Barral et al. 2002; Gern et al. 1999; Guner et al. 2003; Jouda et al. 2003, 2004a, b; Le Fleche et al. 1997; Richter et al. 2003), but subsequent studies seem to highlight a higher heterogeneity (De Michelis et al. 2000; Richter and Matuschka 2006). To date, knowledge on genetic diversity of $B$. lusitaniae is still poor and mostly focused on the rrf (5S)-rrl (23S) intergenic spacer region. Previous studies suggested that this locus is not suitable for analysis of the molecular phylogeny of $B$. burgdorferi s.l. (De Michelis et al. 2000; Postic et al. 1994). In order to characterize and classify Borrelia burgdorferi s.l. 
isolates, scientists often use the outer surface protein A (OspA) gene. It localizes in the linear plasmid lp54 with covalently closed ends (Barbour and Garon 1987) and encodes for a lipoprotein expressed mainly during development in ticks (De Silva and Fikrig 1997) that represents one of the main antigens of $B$. burgdorferi s.l. species (Barbour et al. 1984). A recombinant vaccine has been developed on the basis of this antigen (Schoen et al. 1995). Considering the low level in horizontal plasmid transmission (Dykhuizen et al. 1993), we used the OspA gene sequence to investigate the phylogenetic relationship between our samples and the sequences available in GenBank to infer population structure. To December 2006, OspA sequences of B. lusitaniae deposited in GenBank are partial nucleotide sequences, with the exception of three complete gene sequences (PotiB1, -B2, and -B3; GenBank accession numbers Y10837, Y10838, and Y10839, respectively).

Hence the aim of this study was to create a new, larger dataset of complete OspA gene sequences of $B$. lusitaniae strains from Tuscany and to compare them with all the possible homologue sequences available from GenBank (Fig. 1). Phylogenetic analyses were carried out to investigate and describe heterogeneity of this genospecies in the Mediterranean area.

\section{Materials and Methods}

\section{Sample Collection and DNA Extraction}

Ticks and lizards were collected in a 500-ha enclosed natural reserve in the province of Pisa, Tuscany. Ticks were collected by intensive dragging during three sessions in 2004: May 28 (8 collection sites), July 9 (5 sites), and August 4 (14 sites) (Bertolotti et al. 2006). Lizards and ticks on lizards were collected during four sampling sessions in spring and summer of 2005: May (4 days), June ( 2 days), July (4 days), and August (7 days) (Amore et al. 2007). Both ticks and lizard tissues, obtained by natural tail fracture, were stored in ethanol $70 \%$ until DNA extraction.

DNA was extracted from ticks (previously homogenized with a sterile pestle in microcentrifuge tubes) and from lizard tail biopsies using the Qiagen DNeasy Tissue Kit (Qiagen, Hilden, Germany), in according to the manufacturer's instructions. DNA was suspended in nuclease-free water (50 $\mu \mathrm{l}$ for ticks and $100 \mu \mathrm{l}$ for tissues) (Amore et al. 2007).

\section{PCR Amplification}

Following a multiple alignment of the few OspA of $B$. lusitaniae reference sequences published in the GenBank database, two primers were newly designed on highly conserved regions. The sequences of these primers are: OspAf forward primer, 5'-ATGAAAAAATATTTATTG GGAATA-3'; and OspAr reverse primer, 5'-TTATTT TAAAGCAGTTTTGAGATC- $3^{\prime}$. PCR was carried out in a $50-\mu 1$ reaction volume, using 5- $\mu$ l DNA samples, 2 pmol of each primer, a $200 \mu \mathrm{M}$ concentration of each dNTP, 1.5 $\mathrm{mM} \mathrm{MgCl} 2,1 \mathrm{U}$ of Hot Start Taq DNA polymerase (Qiagen) on an iCycler Thermal Cycler (Bio-Rad, Milan, Italy). Each sample was subjected to an amplification
Fig. 1 Map of origin of samples used in phylogenetic analyses. IT, Italy; DE, Germany; PT, Portugal; MO, Morocco; TN, Tunisia

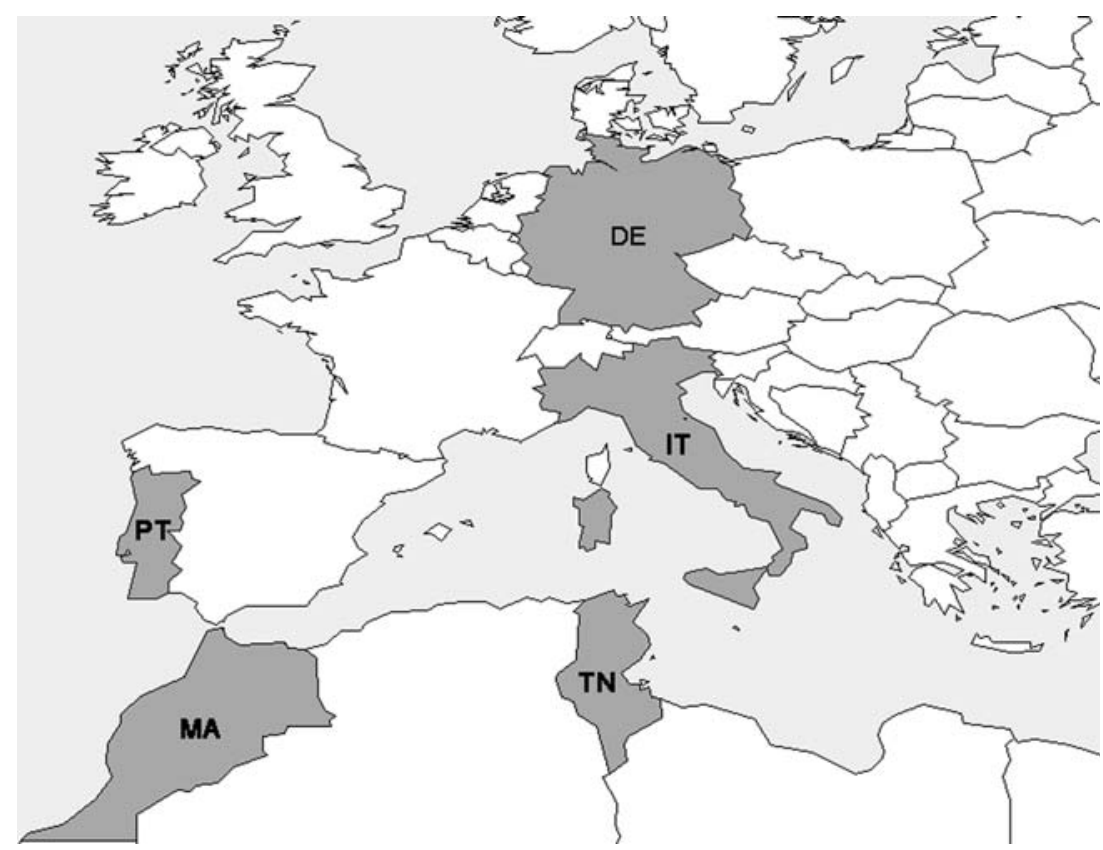


profile of $95^{\circ} \mathrm{C}$ for $15 \mathrm{~min}, 40$ cycles of $94^{\circ} \mathrm{C}$ for $1 \mathrm{~min}$, $50^{\circ} \mathrm{C}$ for $1 \mathrm{~min}$, and $72^{\circ} \mathrm{C}$ for $1 \mathrm{~min}$, and a final extension of $72^{\circ} \mathrm{C}$ for $10 \mathrm{~min}$. Amplicons were analyzed by electrophoresis through $2.5 \%(\mathrm{w} / \mathrm{v})$ agarose gel in TBE buffer and visualized by staining with $0.1 \%$ of ethidium bromide. Negative controls (distilled water) were added to verify the potential contaminations of samples during this phase.

The OspA gene was determined by direct DNA sequencing on both strands of the PCR products by Big Dye terminator cycle sequencing using the amplification primer pair and analyzed on an ABI Prism 3130 Genetic Analyzer (Applied Biosystems, Monza, Italy) according to the manufacturer's protocol. All sequences were hand edited and ambiguous bases resolved by repeated sequencing of both DNA strands.

To describe the diversity in $B$. lusitaniae OspA gene around the Mediterranean basin, all possible OspA gene sequences available in GenBank as of December 2006 were selected.

\section{Phylogenetic Analyses}

Sequences were aligned using the computer program ClustalX (Thompson et al. 1997), following protein alignment, to respect coding frame. Population genetic analyses were carried out with the computer programs Arlequin ver. 3.01 (Excoffier et al. 2005). Analyses of molecular variance (AMOVA; Excoffier et al. 1992) were carried out to investigate geographic subdivisioning within states around the Mediterranean basin. The significance of subdivisions was tested using 16,000 permutations of the data, performed with Arlequin.

Phylogenetic analyses were carried out creating two different trees. To compare the entire gene, the first tree was drawn using new sequences from Tuscany and Portuguese POTI strains. In the second tree, in order to explore the largest possible number of geographic locations, only the common portion of sequence among all sequences available in GenBank was considered. In both cases, a large outgroup of different Borrelia burgdorferi s.l. genospecies was included. To draw trees, we estimated the model of molecular evolution using a hierarchical likelihood ratio test approach and the Akaike information criterion (Akaike 1973) implemented in the computer program ModelTest version 3.7 (Posada and Crandall 1998; D. Posada 2001). Bayesian methods implemented in the computer program MrBayes version 3.1.1 (Huelsenbeck and Ronquist 2001; Ronquist and Huelsenbeck 2003) were used to create phylogenetic trees and assess statistical support for clades. Specifically, a Markov chain Monte Carlo search for 1 million generations using two runs with four chains (temperature $=0.05$ ) was performed and results were represented as a $50 \%$ majority rule consensus tree. Tree statistics and phylogenetic manipulations were performed using the computer program PAUP* version 4.0b10 (Swofford 2003).

To investigate the role of selective pressure in sequence heterogeneity, we evaluated the ratio of nonsynonymousto-synonymous substitutions among samples and Neutrality Index (McDonald and Kreitman 1991) between European and North African strains, using DnaSP software, version 4.10.9 (Rozas et al. 2003). Tests for departure from the neutral expectation were performed using a $G$-test with Williams' correction (Sokal and Rohlf 1981).

\section{Results}

B. lusitaniae is the predominant Borrelia genospecies in the Tuscany area: high infection rates in DNA samples from lizards and in host-seeking ticks were reported in previous studies. Briefly, Bertolotti et al. (2006) reported the prevalence of B. lusitaniae to be $14.0 \%$ and $34.0 \%$ in host-seeking nymphs and adults, respectively. Amore et al. (2007) reported similar results, showing a prevalence of $19.8 \%$ and $52.9 \%$ in larvae and nymphs collected on lizards. DNA from lizard tails and blood showed a prevalence of $18.8 \%$ and $25.0 \%$.

In this study we used a selection of these positive DNA samples (host-seeking Ixodes ricinus, $n=31$; Podarcis muralis lizards, $n=4$; I. ricinus larvae on lizards, $n=9$ ) to analyze the $B$. lusitaniae OspA gene and investigate phylogenetic relationships among samples. All PCR products were sequenced and six different haplotypes of 822 nucleotides were obtained (accession numbers: EF457553 to EF457558). No multiple OspA alleles were found. The frequency of each haplotype and variable sites in new Italian sequences are reported in Table 1.

The phylogenetic tree representing the relationships between new Italian sequences and homologue sequences from the literature is shown in Fig. 2. A clear distinction between Italian and Portuguese POTIB strains was evident and supported by high posterior probability values. All partial sequences of the $B$. lusitaniae OspA gene available in GenBank ( $n=20$ as of December 2006) were aligned and the common portion was selected, in order to create the largest possible dataset of homologue sequences. The partial internal sequence of 267 nucleotides (from 229 to 495 positions of consensus whole-gene alignment) was used to draw the second phylogenetic tree (Fig. 3) with the same analytic protocol. The tree showed a clear separation of B. lusitaniae OspA strains in two different clades. Sequences from Morocco and Tunisia formed a clade with Portuguese POTIB strains, whereas Italian samples were grouped with German and human Portuguese strains. This 


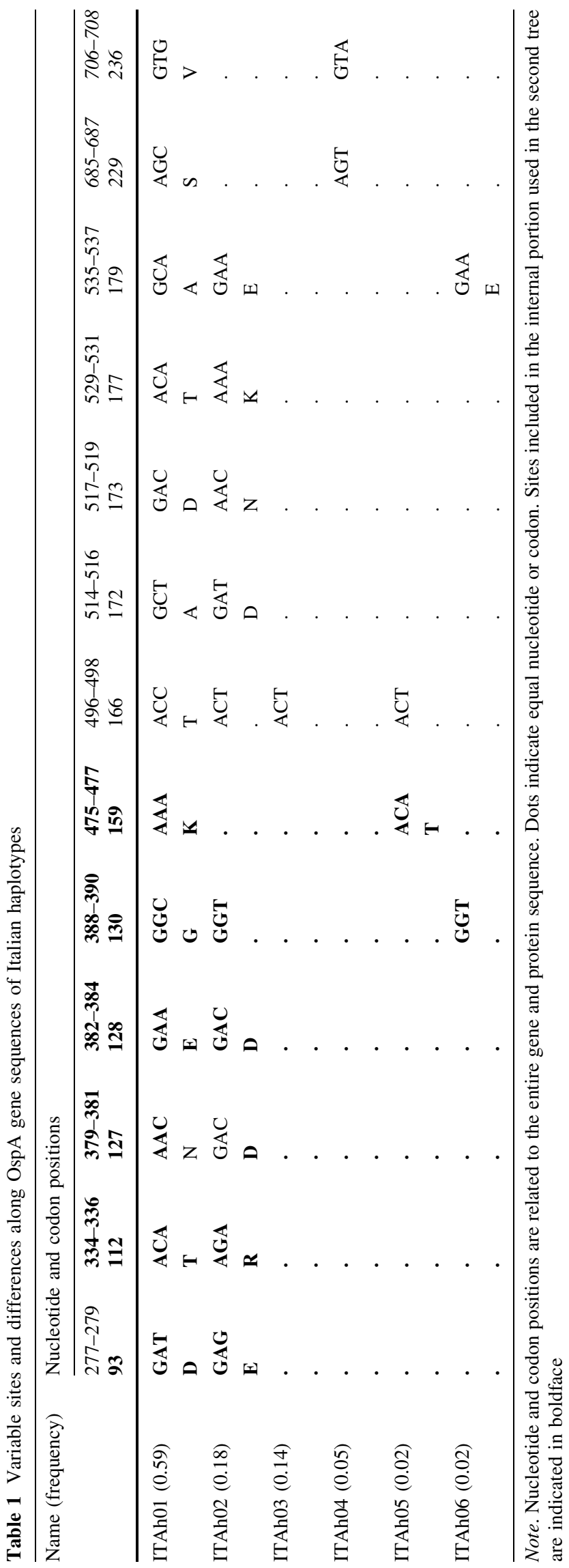

separation is supported by very high posterior probability values.

Clade separations evident in both trees are also reflected by analyzing sequence similarity among taxa, expressed as nucleotide diversity (Nei 1987) and nucleotide and protein alignments. Considering the first alignment, where only complete homologue sequences were included, Italian strains show a $89.67 \%$ mean similarity to POTI strains; in the partial second alignment, both human and German samples show higher mean similarity to Italian strains compared to POTIB and North African strains $(99.02 \%, 99.02 \%$ and $86.22 \%, 85.97 \%$, respectively). The amino acid alignment of the internal gene portion showed several gaps, as reported in Fig. 4. Gaps were conserved among samples belonging to the same geographic area.

To confirm these differences, AMOVA was carried out using the geographical origin as a grouping method. Results, reported in Table 2, confirmed spatial subdivision as suggested by trees, showing a high and significant index of population subdivision $\left(\Phi_{\mathrm{ST}}=0.89, p<0.001\right)$. No correlations among genetic data and host species or vector and collection period were found (data not shown).

Ratio of non-synonymous $(d N)$ to synonymous $(d S)$ substitutions was estimated to evaluate the role of selective pressure on nucleotide diversity among OspA strains. Considering complete sequences, overall $d N / d S$ pairwise average was equal to 0.710 , showing the presence of a moderate purifying selection among new Italian and Portuguese POTIB sequences. To evaluate differences between European and North African strains we calculated $d N / d S$ values within each group, using partial gene sequences following complete protein alignment to respect coding frame. Overall average is similar to complete gene ratio $(d N / d S: 0.680)$. The pairwise $d N / d S$ value among the European samples is higher than the North African one (1.261 and 0.919 , respectively). As reported in Table 3, the index of neutrality indicates an excess of amino acid polymorphism within the two main groups (Rand and Kann 1996), but no significant departures from neutrality are detected $\left(\mathrm{G}_{\text {adj }} p\right.$ value $\left.>0.05\right)$.

\section{Discussion}

B. lusitaniae is by far the most predominant genospecies in Ixodes ricinus ticks on Le Cerbaie Hills (Bertolotti et al. 2006). The interest in Borrelia lusitaniae genospecies is increasing after its isolation from a human patient but little is known about its evolution. In this study, phylogenetic relationship among $B$. lusitaniae isolates around the Mediterranean basin, where this genospecies has been demonstrated to be predominant, was investigated by 
Fig. 2 Phylogenetic tree constructed by Bayesian analysis of 13 Borrelia burgdorferi s.l. OspA gene sequences (length, 822 nucleotides). Posterior probabilities of clades are indicated above branches. New Italian sequences are in boldface

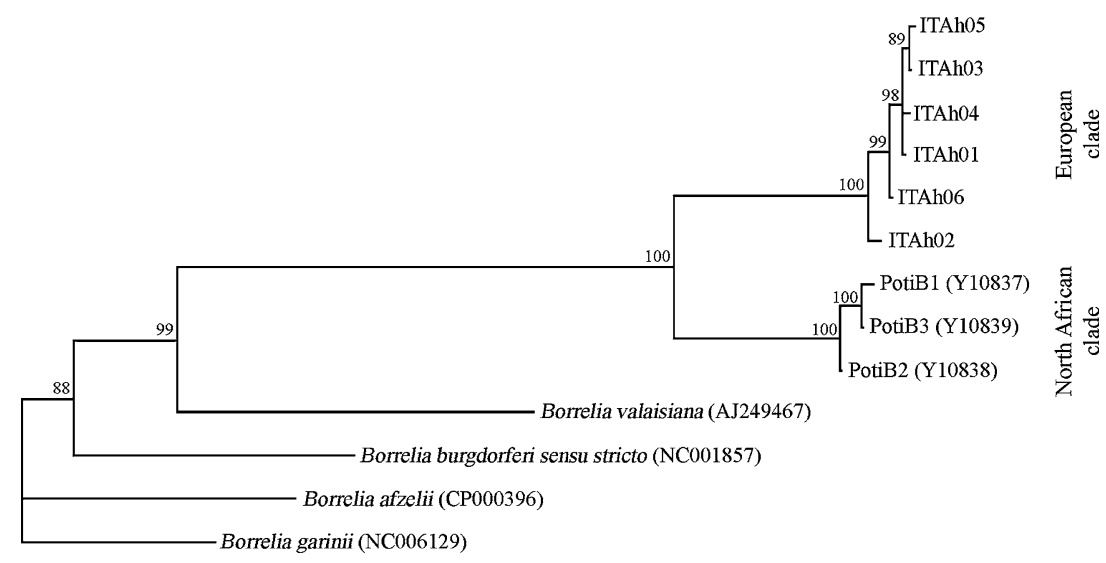

Fig. 3 Phylogenetic tree constructed by Bayesian analysis of 32 Borrelia burgdorferi s.1. OspA gene sequences (length, 267 nucleotides). Posterior probabilities of clades are indicated above branches. New Italian sequences are in boldface

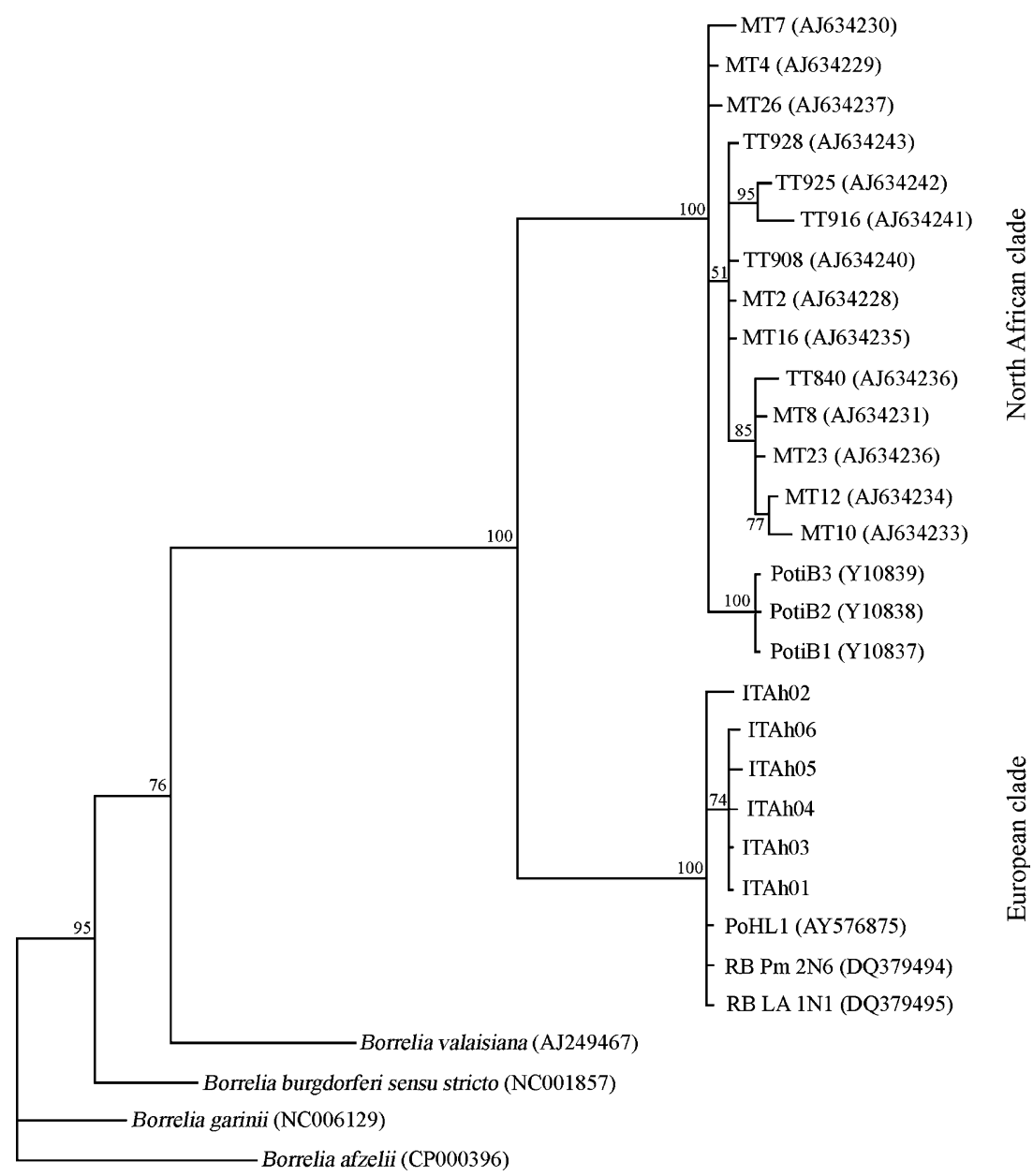

OspA gene analysis. Richter and colleagues (2006) described OspA gene as the most heterogeneous gene in their study. Our results showed a similar situation, describing a clear population subdivision and confirming similarity results between the European and the POTI strains in Richter's study. Indeed, the Italian and German strains show a mean nucleotide diversity equal to $10.33 \%$ and $13.78 \%$ compared to POTI strains, considering complete and partial alignment, respectively. The description of six new haplotypes from the Italian strains significantly increases the global genetic diversity previously known for B. lusitaniae genospecies in this locus.

Sequences from Tuscany and PoHL1 strain isolated from a Portuguese patient belong to the same clade. Above all, haplotype ITAh02 shows a high similarity to the human isolate. This finding highlighted the potential human health risk in Tuscany. Both phylogenetic trees and the AMOVA strongly support the presence of two main strains in $B$. 
Fig. 4 Amino acid alignment of internal gene portion. Gaps are highlighted

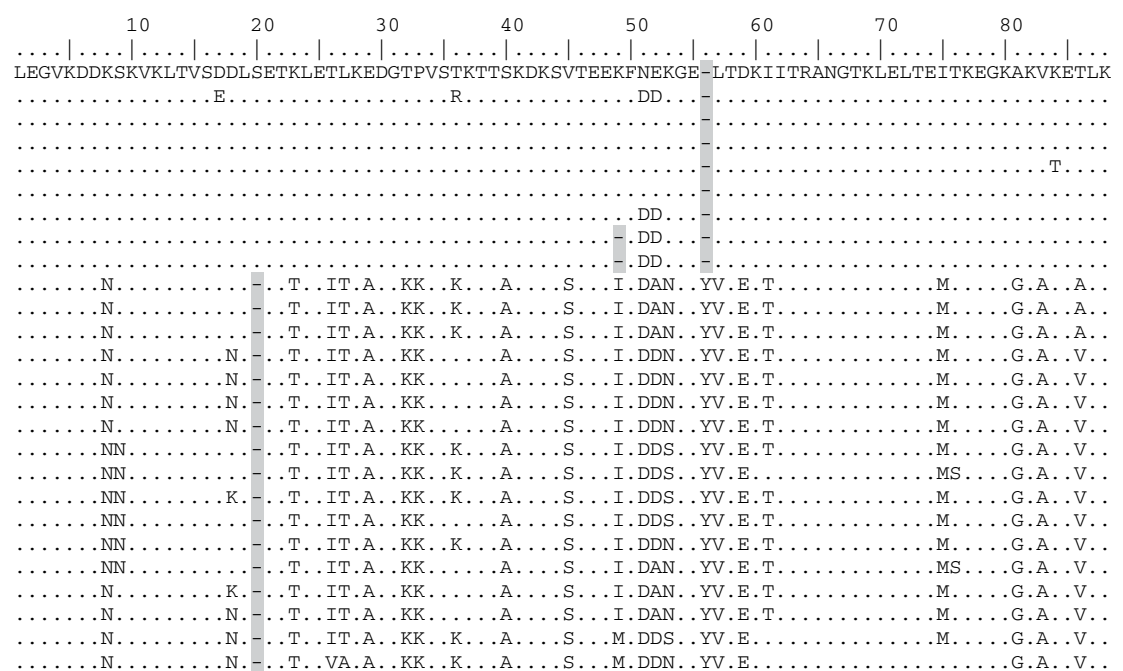

Table 2 Hierarchical analyses of molecular variance (AMOVA) for Borrelia lusitaniae OspA gene sequence data from different geographic locations ${ }^{\mathrm{a}}$

\begin{tabular}{lccccc}
\hline Variance component & $\mathrm{df}$ & Variance & $\%$ total & $p^{\mathrm{b}}$ & $\Phi_{\text {ST }}$ statistic \\
\hline Among countries, ${ }^{\mathrm{c}} \sigma_{\mathrm{a}}^{2}$ & 4 & 12.37 & 89.18 & $<0.0001$ & 0.8918 \\
Within countries, $\sigma_{\mathrm{c}}^{2}$ & 61 & 1.50 & 10.82 & \\
\hline
\end{tabular}

${ }^{a}$ Sequences were divided into country of origin

b Probability of obtaining a more extreme variance component and $\Phi_{\mathrm{ST}}$ statistic than the observed values by chance alone, calculated by 16,000 random permutations of the data, implemented using the computer program ARLEQUIN, version 3.01 (Excoffier et al. 2005)

${ }^{c}$ Sample sizes: Italy $(n=44)$, Portugal $(n=4)$, Germany $(n=2)$, Morocco $(n=10)$, and Tunisia $(n=6)$

Table 3 Silent and replacement differences along common partial sequences of OspA gene within and between European and North African strains

\begin{tabular}{lll}
\hline & $\begin{array}{l}\text { European } \\
\text { strain }(n=9)\end{array}$ & $\begin{array}{l}\text { North African } \\
\text { strain }(n=17)\end{array}$ \\
\hline Silent mutations & 1 & 3 \\
Replacement mutations & 5 & 13 \\
\hline & Fixed differences & Polymorphic \\
\hline Silent & 10 & 3 \\
Replacement & 17 & 17 \\
Neutrality index: & 3333 & $2807(0.094)$ \\
$\quad G_{\text {adj }}(p$ value) & & \\
\hline
\end{tabular}

lusitaniae: a "North African" clade, including samples from Morocco and Tunisia and Portuguese POTIB strains, and a "European" clade, including new Italian sequences, human Portuguese isolates, and samples from Germany. The Portuguese samples belonged to both strains, supporting the geographical origin of this genospecies.

As reported by Poupon and colleagues (2006), B. lusitaniae seems to be carried by migratory birds among different geographic areas. Accordingly, previous studies demonstrated Borrelia reactivation in birds during migration, supporting a temporal role of migratory birds as reservoir hosts (Gylfe et al. 2000). Our results seem to confirm the diffusion of infection through European countries, supported by the high similarity between Italian and German samples. Moreover, the ratio of nonsynonymous-to-synonymous change estimation among Italian and POTI strains shows a slight purifying selection that can be justified as a result of geographical isolation. Comparing a larger dataset, including the short gene portion, the overall result in selection estimation is the same, but a moderate positive selection seems to be present among the European samples. This situation points out a possible distribution and evolution through the Strait of Gibraltar, and through the two different continents separately, involving bird migration pathways and lizards and, eventually, other unknown hosts as reservoir at local level. Future investigations are required to bear out these results and increase knowledge about B. lusitaniae evolution. In order to better understand the relationship between bacterial strains and different hosts, further studies are necessary to investigate B. lusitaniae evolution at local and global levels, in different geographic areas, to gain a deeper understanding of the diffusion ways of this genospecies. 


\section{References}

Akaike H (1973) Information theory and an extension of an extension of the maximum likelihood principle. Proceedings, 2 International Symposium on Information Theory, Budapest, pp 267281

Amore G, Tomassone L, Grego E, Ragagli C, Bertolotti L, Nebbia P, Rosati S, Mannelli A (2007) Borrelia lusitaniae in immature Ixodes ricinus (Acari: Ixodidae) feeding on common wall lizards in Tuscany, central Italy. J Med Entomol 44:303-307

Barbour AG, Garon CF (1987) Linear plasmids of the bacterium Borrelia burgdorferi have covalently closed ends. Science 237:409-411

Barbour AG, Tessier SL, Hayes SF (1984) Variation in a major surface protein of Lyme disease spirochetes. Infect Immun 45:94-100

Barral M, Garcia-Perez AL, Juste RA, Hurtado A, Escudero R, Sellek RE, Anda P (2002) Distribution of Borrelia burgdorferi sensu lato in Ixodes ricinus (Acari: Ixodidae) ticks from the Basque Country, Spain. J Med Entomol 39:177-184

Bertolotti L, Tomassone L, Tramuta C, Grego E, Amore G, Ambrogi C, Nebbia P, Mannelli A (2006) Borrelia lusitaniae and spotted fever group rickettsiae in Ixodes ricinus (Acari: Ixodidae) in Tuscany, central Italy. J Med Entomol 43:159-165

Collares-Pereira M, Couceiro S, Franca I, Kurtenbach K, Schafer SM, Vitorino L, Goncalves L, Baptista S, Vieira ML, Cunha C (2004) First isolation of Borrelia lusitaniae from a human patient. J Clin Microbiol 42:1316-1318

De Michelis S, Sewell HS, Collares-Pereira M, Santos-Reis M, Schouls LM, Benes V, Holmes EC, Kurtenbach K (2000) Genetic diversity of Borrelia burgdorferi sensu lato in ticks from mainland Portugal. J Clin Microbiol 38:2128-2133

De Silva AM, Fikrig E (1997) Borrelia burgdorferi genes selectively expressed in ticks and mammals. Parasitol Today 13:267-270

Dykhuizen DE, Polin DS, Dunn JJ, Wilske B, Preac-Mursic V, Dattwyler RJ, Luft BJ (1993) Borrelia burgdorferi is clonal: implications for taxonomy and vaccine development. Proc Natl Acad Sci USA 90:10163-10167

Excoffier L, Smouse PE, Quattro JM (1992) Analysis of molecular variance inferred from metric distances among DNA haplotypes: application to human mitochondrial DNA restriction data. Genetics 131:479-491

Excoffier L, Estoup A, Cornuet JM (2005) Bayesian analysis of an admixture model with mutations and arbitrarily linked markers. Genetics 169:1727-1738

Gern L, Hu CM, Kocianova E, Vyrostekova V, Rehacek J (1999) Genetic diversity of Borrelia burgdorferi sensu lato isolates obtained from Ixodes ricinus ticks collected in Slovakia. Eur J Epidemiol 15:665-669

Guner ES, Hashimoto N, Takada N, Kaneda K, Imai Y, Masuzawa T (2003) First isolation and characterization of Borrelia burgdorferi sensu lato strains from Ixodes ricinus ticks in Turkey. J Med Microbiol 52:807-813

Gylfe A, Bergstrom S, Lundstrom J, Olsen B (2000) Reactivation of Borrelia infection in birds. Nature 403:724-725

Huelsenbeck JP, Ronquist F (2001) MRBAYES: Bayesian inference of phylogenetic trees. Bioinformatics 17:754-755

Jouda F, Crippa M, Perret JL, Gern L (2003) Distribution and prevalence of Borrelia burgdorferi sensu lato in Ixodes ricinus ticks of canton Ticino (Switzerland). Eur J Epidemiol 18:907912

Jouda F, Perret JL, Gern L (2004a) Density of questing Ixodes ricinus nymphs and adults infected by Borrelia burgdorferi sensu lato in Switzerland: spatio-temporal pattern at a regional scale. Vector Borne Zoonotic Dis 4:23-32
Jouda F, Perret JL, Gern L (2004b) Ixodes ricinus density, and distribution and prevalence of Borrelia burgdorferi sensu lato infection along an altitudinal gradient. J Med Entomol 41:162-169

Le Fleche A, Postic D, Girardet K, Peter O, Baranton G (1997) Characterization of Borrelia lusitaniae sp. nov. by $16 \mathrm{~S}$ ribosomal DNA sequence analysis. Int J Syst Bacteriol 47:921-925

Majlathova V, Majlath I, Derdakova M, Vichova B, Pet'ko B (2006) Borrelia lusitaniae and green lizards (Lacerta viridis), Karst Region, Slovakia. Emerg Infect Dis 12:1895-1901

McDonald JH, Kreitman M (1991) Adaptive protein evolution at the Adh locus in Drosophila. Nature 351:652-654

Nei M (1987) Molecular evolutionary genetics. Columbia University Press, New York

Posada DCKA (2001) Selecting the best-fit model of nucleotide substitution. Syst Biol 50:580-601

Posada D, Crandall KA (1998) MODELTEST: testing the model of DNA substitution. Bioinformatics 14:817-818

Postic D, Assous MV, Grimont PA, Baranton G (1994) Diversity of Borrelia burgdorferi sensu lato evidenced by restriction fragment length polymorphism of $\operatorname{rrf}(5 \mathrm{~S})$-rrl (23S) intergenic spacer amplicons. Int J Syst Bacteriol 44:743-752

Poupon M-A, Lommano E, Humair PF, Douet V, Rais O, Schaad M, Jenni L, Gern L (2006) Prevalence of Borrelia burgdorferi sensu lato in ticks collected from migratory birds in Switzerland. Appl Environ Microbiol 72:976-979

Rand DM, Kann LM (1996) Excess amino acid polymorphism in mitochondrial DNA: contrasts among genes from Drosophila, mice, and humans. Mol Biol Evol 13:735-748

Richter D, Matuschka FR (2006) Perpetuation of the Lyme disease spirochete Borrelia lusitaniae by lizards. Appl Environ Microbiol 72:4627-4632

Richter D, Schlee DB, Matuschka FR (2003) Relapsing fever-like spirochetes infecting European vector tick of Lyme disease agent. Emerg Infect Dis 9:697-701

Ronquist F, Huelsenbeck JP (2003) MrBayes 3: Bayesian phylogenetic inference under mixed models. Bioinformatics 19:1572-1574

Rozas J, Sanchez-DelBarrio JC, Messeguer X, Rozas R (2003) DnaSP, DNA polymorphism analyses by the coalescent and other methods. Bioinformatics 19:2496-2497

Sarih M, Jouda F, Gern L, Postic D (2003) First isolation of Borrelia burgdorferi sensu lato from Ixodes ricinus ticks in Morocco. Vector Borne Zoonotic Dis 3:133-139

Schoen RT, Meurice F, Brunet CM, Cretella S, Krause DS, Craft JE, Fikrig E (1995) Safety and immunogenicity of an outer surface protein A vaccine in subjects with previous Lyme disease. J Infect Dis 172:1324-1329

Sokal R, Rohlf JF (1981) Biometry. W. H. Freeman, San Francisco

Swofford D (2003) PAUP*. Phylogenetic analysis using parsimony (*and other methods). Sinauer Associates, Sunderland, MA

Thompson JD, Gibson TJ, Plewniak F, Jeanmougin F, Higgins DG (1997) The CLUSTAL_X windows interface: flexible strategies for multiple sequence alignment aided by quality analysis tools. Nucleic Acids Res 25:4876-4882

Tomassone L, Bertolotti L, Tramuta C, Nebbia P, Amore G, Ambrogi C (2005) Bacterial tick-borne pathogens in ticks and vertebrate hosts in Tuscany (Italy). In: Proceedings of the 5th International Conference on Ticks and Tick-Borne Pathogens, Neuchatel, Switzerland, pp 220-222

Wang G, van Dam AP, Dankert J (1999) Phenotypic and genetic characterization of a novel Borrelia burgdorferi sensu lato isolate from a patient with lyme borreliosis. J Clin Microbiol 37:30253028

Younsi H, Sarih M, Jouda F, Godfroid E, Gern L, Bouattour A, Baranton G, Postic D (2005) Characterization of Borrelia lusitaniae isolates collected in Tunisia and Morocco. J Clin Microbiol 43:1587-1593 